\title{
Downward Smolder of Polyurethane Foam
}

\section{J. L. TORERO}

Laboratoire de Chimie Physique de la Combustion

Domaine du Deffend

86550 Mignaloux-Beauvoir,

France

A. C. FERNANDEZ-PELLO

Department of Mechanical Engineering

University of California

Berkeley, CA 94720

U.S.A.

M. KITANO

Department of Aeronautics and Space Engineering

Tohoku University

Aramaki, Aoba-ku, Sendai

980 Japan

\begin{abstract}
A study is carried out to determine the controlling mechanisms of natural convection downward smolder through a porous combustible material, and to observe the effect of buoyancy on the propagation of the smolder reaction. Measurements are performed of the smolder reaction temperature and velocity through polyurethane foam as a function of the smolder reaction location and sample size. Three zones with different smolder characteristics can be identified from the measurements. An initial zone where heat transfer from the igniter results in relatively high smolder velocities. A middle zone with an approximately constant, or slightly increasing, smolder velocity, whose length increases with the foam length, considered to be representative of self-propagating somolder in natural convection. A final zone, near the end of the sample, that is characterised by a strong increase in the smolder velocity due to an increase in the flow rate of oxidizer through the sample. A theoretical analysis of the flow field induced by buoyancy through the foam is developed and incorporated to the theoretical model of Dosanjh et al. [1] for opposed forced smolder, and the results of the model are used to correlate the experimental smolder velocity data. The model predicts very well the experimental measurements, and indicates that, for the present experimental conditions, downward smoldering is a process controlled by the supply of oxidizer to the reaction zone.
\end{abstract}

KEYWORDS: Smoldering Combustion, Polyurethane Foam, Natural Convection 
Cp

D

$\mathrm{Gr}_{\mathbf{K}}$

K

$\mathrm{g}$

L

n

$P$

Q

$\dot{\mathrm{q}}_{\mathrm{ig}}^{\prime \prime}$

$R a_{x}$

$\mathrm{Re}_{\mathrm{K}}$

$\mathrm{T}$

$\mathrm{u}_{\mathrm{b}}$

$\mathrm{u}_{\mathrm{g}}$

$\mathrm{u}_{\mathrm{D}}$

$\mathrm{X}$

$\mathrm{Y}$

$\mathrm{y}$

Greek Symbols

$\beta$

$\delta$

$\mu$

$\phi$

$\rho$

$\rho_{\mathrm{CH}}$

\section{Subscripts}

A
C
CH
D
d
F
H
i
O
S
W

Specific heat capacity

Mass Diffusivity of Oxygen in air

Grashof Number $=\frac{K_{C H}^{15} g p_{A}^{2} \beta\left(T_{W}-T_{S}\right)}{\mu^{2}}$

Permeability

Gravitational Acceleration

Length

Number of moles

Pressure

Energy released per mass of $\mathrm{O}_{2}$ consumed

Heat flux from the igniter

Raleigh Number $=\operatorname{Re}_{\mathbf{K}} \mathrm{Gr}_{\mathbf{K}}$

Reynolds Number $=\frac{\rho_{\mathrm{A}} \mathrm{u}_{\mathrm{D}} \mathrm{K}_{\mathrm{CH}}^{0.5}}{\mu}$

Temperature

Velocity induced by the boundary layer

Total average air flow velocity

Smoldering velocity

Velocity induced by natural raft

$x$ co-ordinate

Mass fraction

y co-ordinate

Volume expansion coefficient at constant pressure

Boundary layer thickness

Dynamic viscosity

Void fraction

Density

Effective char density $=\rho_{C h a r}\left(\phi_{-d_{C h}}\right)+\rho_{\text {air }} \phi_{C h}$

Air

Cold

Char

Draft

Diffusion

Polyurethane (solid)

Hot

Initial

Oxygen

Smoldering

Wall 


\section{INTRODUCTION}

Smoldering is a heterogeneous surface combustion reaction that under certain conditions propagates through the interior of porous solid combustibles [2]. Smoldering is generally a weakly reacting phenomena, but it has a particular interest in fire safety because its products of combustion are highly toxic, it is difficult to detect in the interior of the material, and often is the initiation source of fires through the transition from smoldering to flaming.

The exothermic smolder reaction propagates through the porous material in a creeping fashion by transferring heat to the virgin material ahead so that its temperature becomes high enough to initiate the surface combustion reaction. Experiments conducted on opposed forced flow smolder [3-5] indicate that if the smolder reaction is vigorous, process is in general oxygen limited. Under these conditions the rate of heat release, and consequently the rate of smolder propagation, is directly dependent on the flow rate of oxidizer reaching the reaction [3-5,6]. However, if the smolder reaction is weak, the characteristics of the reaction become very sensitive to both the rate of oxygen flow to the reaction, and of heat loss from the reaction, with the latter being particularly important $[3,7]$.

Considerable work has been conducted to date on smoldering; reviews of the subject can be found in the works of Ohlemiller [1] and Drysdale [8]. Most studies, relevant to the present work, aim to the identification of parameters controlling the propagation of the smolder reaction such as oxidizer supply and heat losses [4-13]. Limited attention has been given, however, to the effect of buoyancy on the flow structure inside the porous medium and its effect on the smolder process. Dosanjh et al. [1] studied the effect of buoyancy on downward smoldering of powder cellulose by varying the ambient pressure. Torero et al. [3], using polyurethane foam, studied the effect of buoyancy on opposed forced flow smoldering. Cantwell and Fernandez-Pello [14,15] and Torero et al. [16] conducting experiments in a drop tower and aircraft following a parabolic trajectory, made some preliminary observations of the effect of gravity on the smolder characteristics of polyurethane foam. The results corroborate, in general, the above referred observations concerning the effects of oxidizer and heat transport on the smolder process.

In the present work a study is conducted of the free convection, downward propagation of a smolder reaction through flexible polyurethane foam, with the objective of determining the controlling mechanisms of smolder in natural convection.

\section{EXPERIMENTAL APPARATUS}

A schematic diagram of the experimental apparatus is shown in Fig. 1. It consists of a $450 \mathrm{~mm}$ long vertical duct with a $150 \mathrm{~mm}$ side square cross section, made of insulating $10 \mathrm{~mm}$ thick Fiberfax walls mounted on an Aluminium frame. The duct is divided into two sections, one $300 \mathrm{~mm}$ long containing the fuel, and another $150 \mathrm{~mm}$ long containing the igniter and insulating char. The duct width is selected to ensure a one dimensional smolder propagation in a region of at least $50 \mathrm{~mm}$ in diameter from the sample centerline. Foam samples of different lengths are used to determine the effect of scale on the foam smolder. The fuel used 


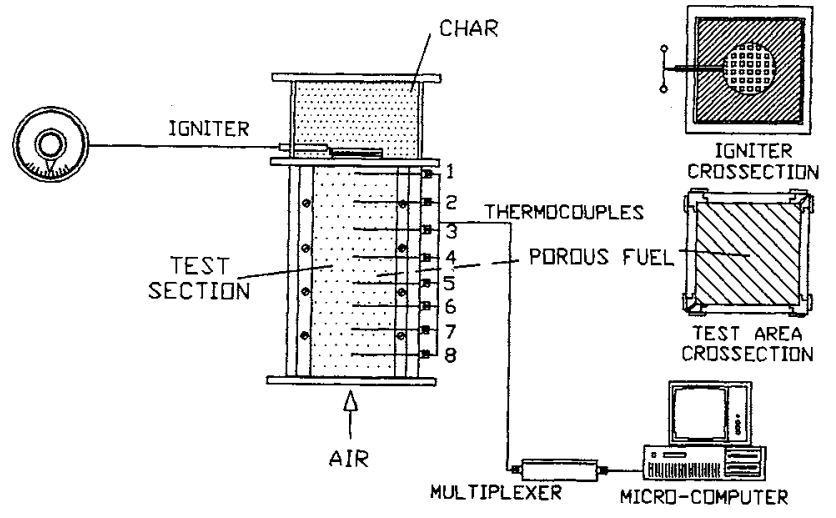

FIGURE 1.

Schematic of the experimental apparatus.

FIGURE 2.

Temperature histories from eight thermocouples, downward smoldering, $200 \mathrm{~mm}$ sample.

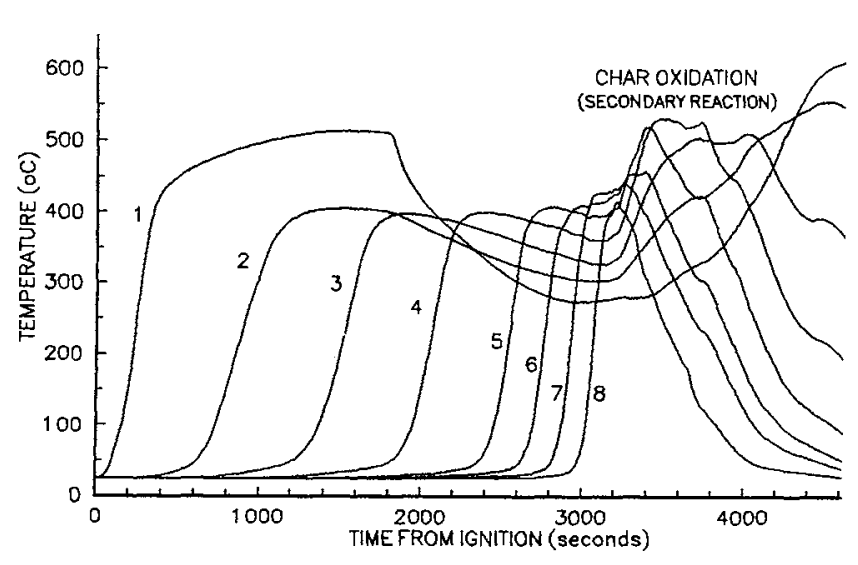

in the experiments is an open cell, unretarded, white polyurethane foam, with a $26.5 \mathrm{Kg} / \mathrm{m}^{3}$ density and 0.975 void fraction. The char is from an already smoldered sample.

The igniter consists of a Nichrome wire sandwiched between two, $5 \mathrm{~mm}$ thick, porous ceramic honeycomb plates. The igniter and a $150 \mathrm{~mm}$ long char are contained in the duct section mounted on top of the fuel section, so that the igniter is in contact with the foam. The char is used to insulate the ignition zone and simulate an ongoing smolder process.

The rate of smolder propagation is obtained from the temperature histories of eight Chromel-Alumel thermocouples $0.8 \mathrm{~mm}$ in diameter embedded at predetermined positions in the porous fuel with their junction placed at the fuel centerline. The smolder velocity is calculated from the time lapse of reaction zone arrival to two consecutive thermocouples, and the known distance between the thermocouples [3]. These thermocouples are also used to obtain the maximum reaction zone temperatures. 


\section{EXPERIMENTAL RESULTS}

The experiments are performed with foam samples of $150 \mathrm{~mm}$ side square cross section and heights of $150 \mathrm{~mm}, 175 \mathrm{~mm}, 200 \mathrm{~mm}$, and $300 \mathrm{~mm}$. Smaller samples were also tested, but the smolder was so influenced by end-effects that the data did not provide useful information about the self-propagation of the smolder reaction, and consequently they are not presented here.

A characteristic example of the temperature histories measured with the thermocouples is given in Fig. 2. The first thermocouple is in contact with the igniter, the next four are spaced $30 \mathrm{~mm}$ apart and the last three $15 \mathrm{~mm}$ apart. The rapid drop in temperature of the igniter thermocouple reflects the switch off of the igniter, and the initiation of self supported smolder. The arrival of the reaction zone is characterised by a maximum in the temperature profile and if heat losses are small, the temperature of the char behind the reaction remains constant. In some cases second temperature maximums are observed in the char as the primary smolder reaction reaches the lower end of the foam.

The measured smolder propagation velocities at different locations along the foam sample are presented in Fig. 3. Each data point is an average from six tests, and the bars indicate the maximum deviation from the mean. From these data, three zones along the foam sample with different smolder characteristics are identified. An initial zone (I) approximately $40 \mathrm{~mm}$ long where the smolder is influenced by heat transfer from the igniter, and where the smolder velocities are consequently somewhat elevated. A second zone (II) in the middle of the sample, of a length that increases as the sample length is increased, which has a smolder velocity that is constant or increases slightly. The minimum of the smolder velocity is approximately the same for all sample lengths. Finally there is a third zone (III), approximately $50 \mathrm{~mm}$ long, that is characterised by a strong increase in the smolder velocity. The length of this third zone is independent of the sample length, and although the smolder velocity increases strongly toward the end of the sample, no transition to flaming was observed in any of these experiments. The magnitudes of smolder velocities agree with others previously reported $[4,5,9,10]$.

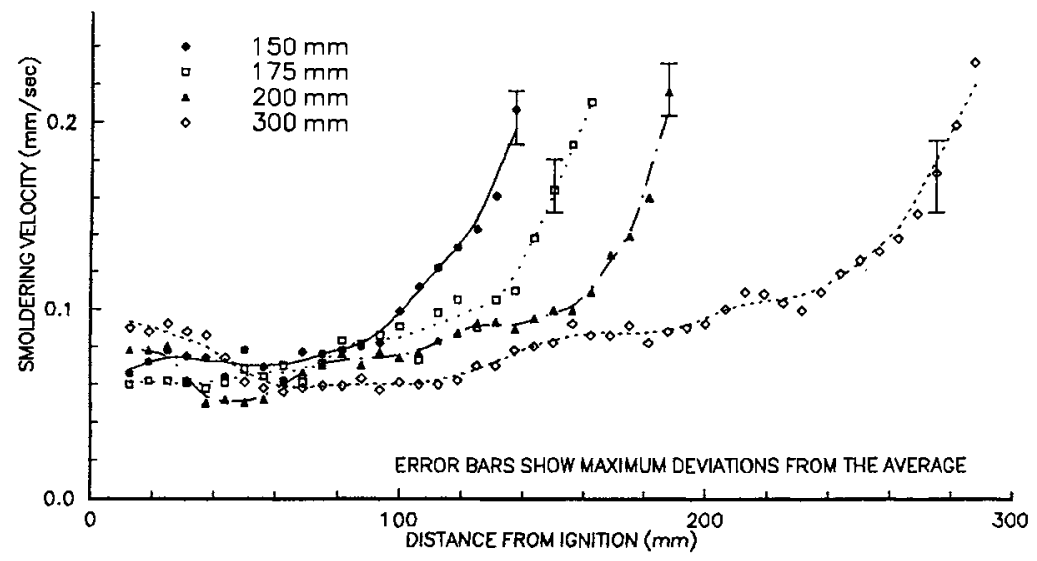

FIGURE 3. Variation of the smolder propagation velocity with the distance from ignition. 
The variation of the smolder reaction maximum temperature along the sample length is presented in Fig. 4. Although less well defined than for the smolder velocity, these data also show the presence of the three zones indicated above. An initial zone near the igniter of elevated temperatures that decrease as the smolder reaction propagates into the sample, and that clearly shows the igniter influence on the smolder reaction. A middle zone where the temperatures are approximately constant or increase slightly. A final zone, at the end of the sample, where the temperature increases at a slightly higher rate. In most of the experiments, secondary reactions in the char were observed after the smoldering front had reached the end of the sample. In those cases the smolder reaction would propagate almost to the end of the sample and would be immediately followed by a secondary reaction propagating upward through the char at increased speed. These char oxidation reactions propagate much faster than the primary smolder reactions and are characterised by higher temperatures. The onset of these secondary reactions and the their sequence is clearly observed from the temperature histories presented in Fig. 2.

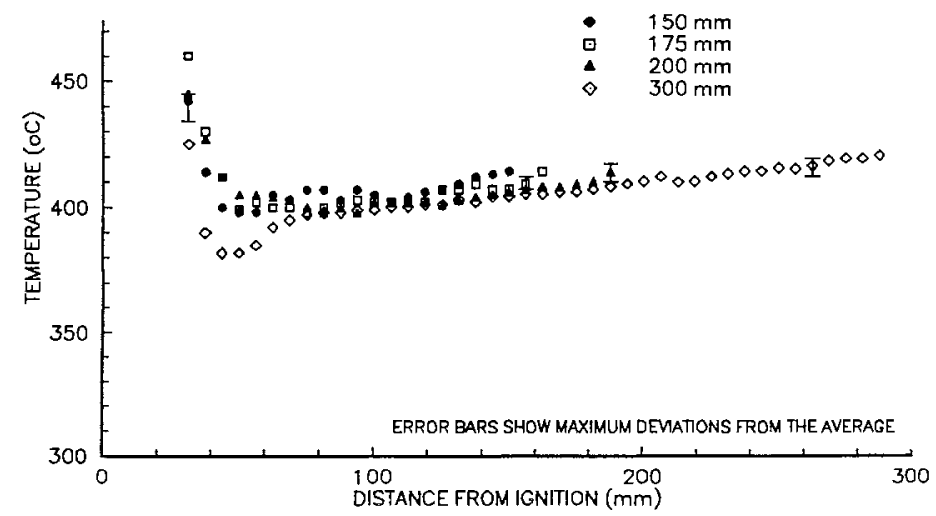

FIGURE 4. Variation of the smolder maximum temperature with the distance from ignition.

\section{THEORETICAL MODEL}

\section{Energy Analysis}

The smoldering reaction propagates downward, against the flow of oxidizer, thus is of the opposed type. Thus, theoretical models developed for forced opposed flow smoldering can be used in an attempt to correlate the experimental data. For this purpose the theoretical model of opposed flow developed by Dosanjh et al. [1] is used in this work. A detailed description of the model and its application to the present configuration can be found in the works of Dosanhj et al. [1] and Torero et al. [3,19]. Solving the appropriate energy conservation equation the following expression for the smolder velocity is obtained. The nomenclature is indicated in the list of symbols.

$$
\mathrm{U}_{\mathrm{S}}=\frac{\rho_{\mathrm{A}}\left[\mathrm{QY} \mathrm{Y}, \mathrm{i}-\mathrm{Cp}_{\mathrm{A}}\left(\mathrm{T}_{\mathrm{S}}-\mathrm{T}_{\mathrm{i}}\right)\right] \mathrm{u}_{\mathrm{g}}+\dot{\mathrm{q}}_{\mathrm{ig}}^{*}(\mathrm{x})}{\rho_{\mathrm{F}} \mathrm{C}_{\mathrm{P}_{\mathrm{F}}}(1-\phi)\left(\mathrm{T}_{\mathrm{S}}-\mathrm{T}_{\mathrm{i}}\right)}
$$


Unknowns in equation (1) are the smolder temperature $T_{S}$, the oxidizer velocity $u_{g}$, and the heat of combustion for smoldering $Q$. The analysis of Dosanjh et al. [1] provides an expression for the smolder temperature $T_{S}$. However, the asymptotic analysis leading to that expression imposes a number of restrictive conditions that are often not applicable to the experiments. For this reason, in this work, the value of the smolder reaction temperature is obtained from the experimental data of Fig. 4. The heat of combustion $Q$, is not well determined for smoldering combustion [2], in this work it will be selected so that the correlation of the experimental data with the above equation is optimised. The resulting value agrees well with those previously reported $[1-5,9,10]$. Finally, since the oxidizer may be induced through the foam by buoyancy, the velocity $u_{g}$ must be determined by calculating the potential buoyant flows that can be generated in the duct, foam or char. This is done in the next section.

\section{Oxidizer Flux Analysis}

The mass flux of oxidizer at the smolder reaction zone is a combination of the flow induced upward through the foam by the natural draft in the duct, the boundary layer flow generated at the duct walls by the temperature gradient between the cold walls and the hot char, the oxidizer flux resulting from the propagation of the reaction into the porous fuel, and the diffusion of oxidizer to the reaction zone (Fig. 5). These different fluxes will be determined individually and afterward superimposed to calculate the overall oxidizer mass flux at the reaction zone.

Natural Draft Through a Duct The natural draft induced through the porous foam by the density difference between the hot gases in the duct and the cold air outside can be treated as a one dimensional problem where the equation for conservation of momentum is substituted by Darcy's formulation $[18,20,21]$.

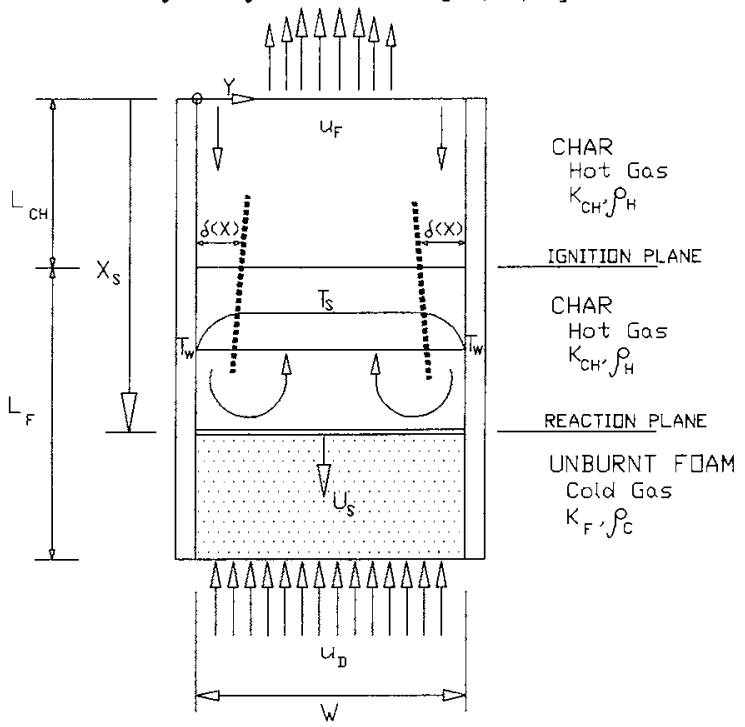

FIGURE 5.

Schematic of the flow field induced by buoyancy. 
Since the virgin foam and the char have very different permeabilities [3], Darcy's equation is then integrated in two separated regions, the unburnt foam region and the char region and the following expression is obtained for the average velocity induced by natural draft through the duct [19].

$$
\mathrm{u}_{\mathrm{D}}=\frac{\mathrm{g}\left(\rho_{\mathrm{H}}-\rho_{\mathrm{C}}\right) \mathrm{x}}{\left.\frac{\mu}{\mathrm{K}_{\mathrm{F}}}\left[\left(\mathrm{L}_{\mathrm{F}}+\mathrm{L}_{\mathrm{CH}}-\mathrm{x}\right)+\left(\frac{\mathrm{K}_{\mathrm{F}}}{\mathrm{K}_{\mathrm{CH}}}\right)\left(\frac{\phi_{\mathrm{F}}}{\phi_{\mathrm{CH}}}\right)^{2 / 3}\left(\frac{\mathrm{n}_{\mathrm{H}}}{\mathrm{n}_{\mathrm{C}}}\right) \frac{\mathrm{T}_{\mathrm{S}}}{\mathrm{T}_{\mathrm{i}}}\right) \mathrm{x}\right]}
$$

Boundary Layer Flow

The temperature of the walls and adjacent gas is lower than that of the post-combustion gases in the interior region of the char which generates a natural convection boundary layer flow at the duct walls. The gases in this boundary layer are primarily composed of fresh ambient air that is entrained at the duct upper edge, and they flow downward toward the reaction zone where the higher pressure losses of the unburnt material forces them to turn inward and join, after reacting with the fuel, the upwardly moving postcombustion gases.

Since the hot post-combustion gases flowing through the duct are primarily the result of the duct generated natural draft, for the boundary layer flow calculations this flow can be viewed as an external forced flow. Based on previous analysis of mixed flow in porous media [2023], the following expression is obtained for the flow averaged velocity along the center region of the foam [19].

$\mathrm{u}_{\mathrm{b}}=\frac{2 \times \mathrm{Ra}_{\mathrm{x}}^{-0.5}}{\mathrm{~W}}\left(\frac{\mathrm{Gr}_{\mathrm{K}}}{\operatorname{Re}_{\mathrm{K}}}\right) \mathrm{u}_{\mathrm{D}}$

\section{Diffusion of Oxidizer}

The gradient of oxidizer concentration between the ambient and the reaction zone will result in a diffusion generated mass flux of oxidizer at the reaction zone. The influence of this flux on the smolder reaction depends on its magnitude relative to that induced by buoyancy, $\mathrm{u}_{\mathrm{D}}$. This comparison can be made by first determining the characteristic length required for the diffusion mass flux to be comparable to the other problem mass fluxes, and then comparing it with the actual length where the concentration gradient exists.. Normalisation of the one dimensional species conservation equation gives the following expression for the characteristic length for which diffusion is comparable to convection [19]

$\delta_{d}=\frac{D}{u_{D}+u_{b}+\phi U_{S}}$

the resulting value for this characteristic length is approximately $5 \mathrm{~mm}$, which is much smaller than the actual experimental one $\left(\mathrm{L}_{\mathrm{F}}\right)$. Thus, the transport of oxidizer to the reaction is dominated by convection, with diffusion having a secondary importance.

Overall Oxidizer Flow Rate at the Reaction

The overall oxidizer flow rate at the reaction zone is given by the addition of the flows due to the duct induced draft, the cold 
wall induced boundary layer, and the relative oxidizer velocity resulting from the propagation of the reaction into the oxidizer contained in the fuel pores. Thus the total oxidizer flow rate at the reaction zone, $u_{\mathrm{g}}$, can be expressed as

$u_{g}=u_{D}+u_{b}+\phi U_{S}$

where $u_{D}$ and $u_{b}$ are given by equations (3) and (4) respectively, and $U_{S}$ is obtained from the experimental data. The resulting variation of the oxidizer flow velocity along the sample height is given in Fig. 6. The property values used in the calculations are $C_{P_{F}}=1.700 \mathrm{KJ} / \mathrm{Kg}$, $\mathrm{K}_{\mathrm{CH}}=8.40 \times 10^{-7} \mathrm{~m}^{2}, \mathrm{~K}_{\mathrm{F}}=2.76 \times 10^{-9} \mathrm{~m}^{2}, \mathrm{Q}=3,900 \mathrm{KJ} / \mathrm{Kg}, \mathrm{n}_{\mathrm{C}}=0.7550$ moles, $\mathrm{n}_{\mathrm{H}}=2.872$ moles, and air at $T_{1}=293 \mathrm{~K}$. It is seen that the predicted oxidizer flow velocity increases strongly as the smolder reaction reaches the end of the sample.

\section{DATA CORRELATION AND DISCUSSION}

In this section the theoretical calculations of the smolder velocity are compared with the experimental data to verify the model predictions, and to determine the smolder controlling mechanisms. The oxidizer velocity along the sample length is obtained with equation (5), or equivalently from Fig. 6.

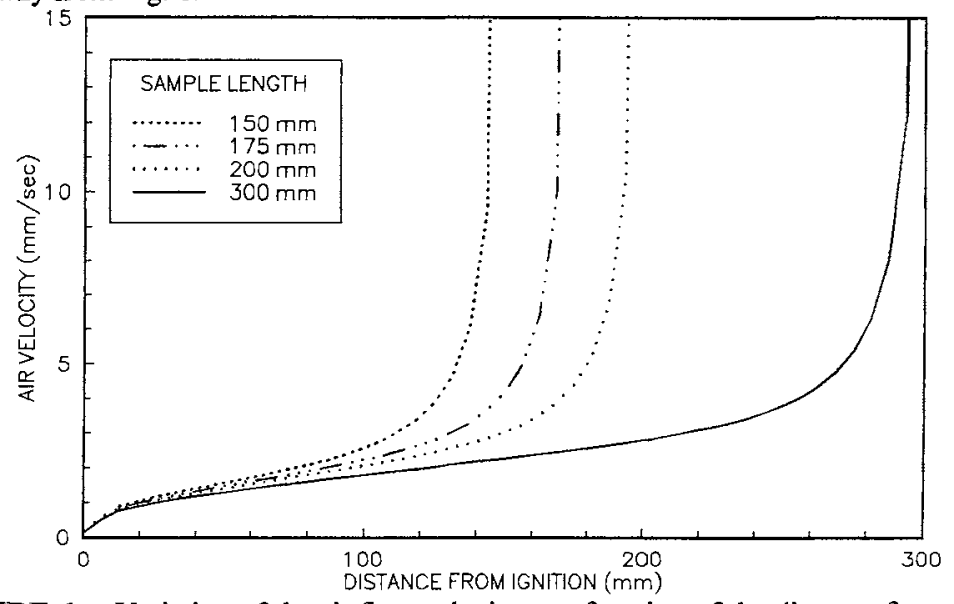

FIGURE 6. Variation of the air flow velocity as a function of the distance from ignition.

The predictions of equation (1) can be used to explain the smolder velocity results of Fig. 3. In zone I, the igniter effect is reflected primarily through an increase in the foam initial temperature and the igniter heat flux. This pre-heating effect appears in equation (1) through $\mathrm{T}_{\mathrm{i}}$ and $\mathrm{q}_{\mathrm{ig}}$ and the model predicts a smolder velocity that decreases as the initial temperature of the foam decreases. The predicted flow rate in this first zone is approximately constant. Thus, equation (1) predicts a smolder velocity that decreases as the reaction progresses away from the igniter as observed in the experiments (Fig. 3). In zone II, the igniter effect is no longer noticeable, and as it is seen from Fig. 6, the oxidizer flow rate reaching the reaction zone increases only slightly as the distance from the igniter increases. Thus, according to 
equation (1) the smolder velocity should increase only weakly. In zone III, as it seen from the oxidizer velocity calculations of Fig. 6 , the oxidizer supply increases sharply as the reaction propagates toward the sample's end, and as predicted by equation (1) the smolder velocity will also increase sharply toward the end of the sample (Fig. 3).

The smolder velocities calculated with equation (1) can be used to correlate in a more quantitative fashion the experimentally measured smoldering propagation velocities presented in Fig. 3. The result of the correlation is presented in Fig. 7. It is seen that the model predicts very well the variation of the smolder velocity. The good agreement between theory and experiments verifies that the smolder controlling mechanisms and simplifying assumptions implicit in the model are appropriated at least for the present experimental conditions.

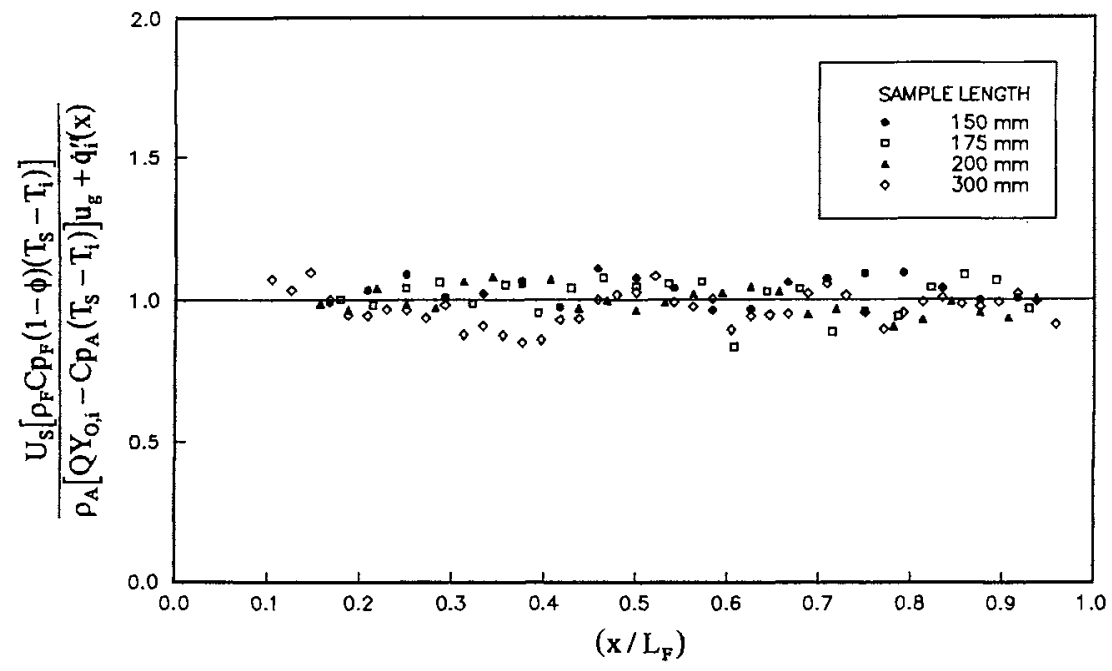

FIGURE 7. Correlation of experimental and theoretical smoldering propagation velocities

One of the models most severe assumptions is that of fast chemistry and total oxygen depletion at the reaction zone. The good agreement between theory and experiments indicates that the smolder reaction in these experiments is vigorous enough for the rate of propagation to be controlled primarily by the rate of heat release at the reaction, which in turn is controlled by the rate of oxygen supply. Furthermore, heat losses to the surrounding environment appear to have a secondary importance.

The verification that in the present experiments the smolder process is oxygen limited, and that consequently all the oxidizer reaching the reaction zone is consumed helps explaining the onset of the secondary reactions in the char. As the smolder wave propagates through the sample, it leaves behind a char whose combustible material content is significant (often a large percentage of the original fuel). This char is a predominantly carbonaceous material of highly exothermic oxidation [2]. Furthermore, the surface area and permeability of the material is larger than that of the original fuel, mainly due to pores formation, and its temperature is almost as high as the reaction temperature, if the heat losses are small. As a consequence, 
when the primary reaction reaches the end of the sample and the oxygen in the air is no longer consumed at the reaction, a flow of fresh air, induced by natural convection, will flow upward through the char. The added oxidizer will cause the char to smolder with the same characteristics of upward smoldering [12,19], but with a stronger reaction due to the fact that there is more oxygen available, the fuel has a larger surface area, and that it has already been preheated by the primary reaction.

\section{CONCLUDING REMARKS}

Away from extinction, the characteristics of smolder reactions, and their rate of propagation, are determined by a balance between the rate of oxygen supply to the smolder reaction, and the rate of heat transfer to, and from, the reaction $[2,3]$. The results of the present experiments indicate that, at least for moderate size polyurethane foam samples, natural convection downward smolder is controlled primarily by the supply of oxidizer to the reaction zone, with the heat losses playing a lesser role.

It should be pointed out that the characteristics of these results could be affected by the presence of different external sources or experimental parameters. For example, a lower heating input from the igniter could result in a weaker initial smolder reaction. Such reaction could be more sensitive to heat losses and consequently could lead to extinction toward the end of the sample [3]. Similarly, if the sample height is very large, or its thickness very small, the reduced buoyant oxidizer supply in the sample interior or the heat losses to the environment, respectively, could result in an initially weak reaction that would also tend to extinction toward the end of the sample. The opposite would occur if the initial temperature of the foam and ambient oxidizer was higher, or if the oxygen concentration was higher.

Although the results from the present work are specific for a particular fuel and ambient conditions, they have provided added information about the controlling mechanisms of natural convection smolder. They also have provided verification of the predictive capabilities of current theoretical models of opposed flow smolder.

\section{ACKNOWLEDGEMENTS}

This work was supported by the National Aeronautics and Space Administration under Grant No. NASA NAG3-443. During the performance of the experiments M. Kitano was a visiting scholar and J.L. Torero was a graduate research assistant at the University of California, Berkeley.

\section{REFERENCES}

1. Dosanjh, S.S., Pagni, P.J. and Fernandez-Pello, A.C.,"Forced Cocurrent Smoldering Combustion," Combustion and Flame, 68, 131-142, 1987.

2. Ohlemiller, T.J.,"Modeling of Smoldering Combustion Propagation," Progress in Energy and Combustion Science, 11, 277-310, 1986. 
3. Torero, J.L., Kitano, M. and Fernandez-Pello, A.C.,"Opposed Forced Flow Smoldering of Polyurethane Foam," Combustion Science and Technology, 91, 95-117, 1993.

4. Ohlemiller, T.J. and Rogers, F.E., "A Survey of Several Factors Influencing Smoldering Combustion in Flexible and Rigid Polymer Foams," Journal of Fire and Flammability, 9, 489-509, 1978.

5. Rogers, F.E. and Ohlemiller, T.J., "Smolder Characteristics of Polyurethane Foams," Journal of Fire and Flammability, 11, 32-44, 1980.

6. Moussa, N.A., Toong, T.Y. and Garris, C.A., "Mechanisms of Smoldering of Cellulosic Materials," Sixteenth Symposium (International) on Combustion, The Combustion Institute, 525-531, 1967.

7. Sato, K. and Sega, S., "Effects of Oxidising Agent Flow on Combustion Spread of Cellulosic Material," Annual Meeting of the Japanese Assoc. of Fire Science and Engineering, 92-102, 1987.

8. Drysdale, D., An Introduction to Fire Dynamics, p.256, John Wiley and Sons, New York, 1987.

9. Ohlemiller, T.J., Bellan, J. and Rogers, F.E., "A Model of Smoldering Combustion Applied to Flexible Polyurethane Foams," Combustion and Flame, 36, 197-215, 1979.

10. Rogers, F.E., Ohlemiller, T.J., Kurtz, A. and Summerfield, M., "Studies of the Smoldering Combustion of Flexible Polyurethane Cushioning Materials," Journal of Fire and Flammability, 9, 5-13, 1978.

11. Summerfield, M. and Mesina, N., "Smoldering Combustion in Porous Fuels," Progress in Astronautics and Aeronautics, 73, 129-194, 1981.

12. Ohlemiller, T.J. and Lucca, T.A., "An Experimental Comparison of Forward and Reverse Combustion," Combustion and Flame, 54, 131-147, 1983.

13. Ohlemiller, T.J., "Smoldering Combustion Propagation Through a Permeable horizontal Fuel Layer," Combustion and Flame, 81, 341-354, 1990.

14. Cantwell, E. and Fernandez-Pello, A.C., "Smoldering Combustion Under Low Gravity," AIAA Paper 90-0648, Jan.1990.

15. Cantwell, E. and Fernandez-Pello, A.C., "Smoldering Combustion Under Low Gravity Conditions," Paper 90-42, 1990 Fall Meeting, Western States Section/The Combustion Institute, San Diego, CA, 1990.

16. Torero, J.L., Fernandez-Pello, A.C. and Urban, D., "Experimental Observations of the Effect of Gravity Changes on Smoldering Combustion," AIAA paper 93-0829, 1993.

17. Ozisik, M.N., Heat Conduction, John Wiley and Sons, New York, 1980.

18. Darcy, H., Les Fontaines Publiques de la Ville de Dijon, Victor Dalmont, Paris, 1856.

19. Torero, J.L., "Buoyancy Effects on Smoldering Combustion of Polyurethane Foam," Ph.D. Thesis, University of California, Berkeley, 1992.

20. Bejan, A., Convection Heat Transfer, John Wiley and Sons, New York, 1984.

21. Nield, D.A. and Bejan, A., Convection in Porous Media, Springer-Verlag, New York, 1992.

22. Lai, F.C., Prasad, V. and Kulacki, F.A.,"Mixed Convection in Saturated Porous Media," Convective Heat and Mass Transfer in Porous Media. Kluwer Academic, Dordrecht, 255-287, 1991.

23. Hadim, A. and Govindarajan, S., "Development of Laminar Mixed Convection in a Vertical Porous Channel," ASME. Heat Transfer Division, 105, 145-153, 1988. 